\title{
METAPHYSICS IN ARISTOTLE'S EMBRYOLOGY
}

\section{Introductory}

Traditionally, discussion of Aristotle's metaphysics, including his theory of form and the 'what it is to be' any given substantial object, has dealt extensively with relevant texts in the Categories, Physics, De anima and, of course, the Metaphysics itself. But the biological works have been largely neglected as sources for knowledge about and insight into Aristotle's theory.' This seems to me unfortunate. In his biological works Aristotle invokes the form of an animal constantly and in interesting physical and, one would have said, metaphysical detail, as the explanation for much, and that the crucial part, of what happens to it as it develops to maturity and maintains and reproduces itself. One would expect these explanations to reveal something about the character of Aristotelian forms and perhaps even to help resolve some of the many questions not clearly settled by him in his metaphysical writings. It might, I suppose, be argued, on the contrary, that Aristotle thought that the notion of form needed for metaphysical purposes is quite distinct from that needed in order to explain the biological phenomena addressed in the Parts and the Generation of Animals. Conceivably there is no, or only a very loose, systematic connection between what is said about forms in the two sets of works, so that one is not entitled to infer metaphysical consequences consequences for the nature of forms as they appear and are argued about on metaphysical terrain - from what forms are taken to be like in the biological context. I will not attempt to argue against this line of interpretation here. In the belief that the philosophical interest of doing so will be sufficient justification, I will simply proceed on the natural assumption that Aristotle did intend his biological theory of forms to be a continuous development and extension of whatever theory of substantial forms he meant to be the upshot of his discussion in the central books of the Metaphysics. ${ }^{2}$

I want to focus upon Aristotle's theory of animal reproduction and embryology in the Generaton of Animals $(G A)$ - his account of how an offspring is brought into being and made to resemble other members of its species in general, as well as its parents and various of its ancestors in particular. As is well known, Aristotle holds that it is a parent's form (more specifically, the father's form) that controls the offspring's formation as a member of the same species. But in that process, it also regularly happens that there come to be parental and more 
generally familial resemblances in the specific ways in which form becomes realized in the offspring. It is perhaps less well known that Aristotle holds that the parental form controls those resemblances, or some of them, as well. To the extent that the parental form is responsible for resemblances to parents and ancestors going beyond mere membership in the same species, and that these resemblances are not due instead to characteristics of the matter on which the form works, or to environmental conditions during or after gestation, one would apparently have to attribute to the parental form certain determinate powers that go beyond those that could belong to a form merely in virtue of the fact that it was a form of a member of that species. In that case the parent's form would have to be, not species-specific merely, but in some additional degree specific for particular further characteristics of bodily structure and organization - whichever ones require to be explained as deriving directly from the parent's formative rôle in generating the offspring.

Now this result does not sit well with either of the two currently most favoured interpretations of the theory of substantial form to be found in Aristotle's metaphysical writings. Many who write on Aristotle's metaphysics seem almost to take it for granted that Aristotelian forms go with species, with natural kinds, one for each. Yet those who have recently revived the ancient interpretation according to which each individual substance has its own individual form, have tended to hold that the features that distinguish one individual form from another, for members of the same species, lie outside the form itself as accidental properties of the substance whose form it is. ${ }^{3}$ If I am right, neither of these interpretations can accommodate the evidence for his conception of forms provided by Aristotle's embryology. In order to show this it will be necessary first to consider that evidence in considerable detail.

\section{Aristotle's theory of animal reproduction}

In the discussions making up the first three books of the $G A$ Aristotle's principal goal is to explain what Montgomery Furth has called the "whacking great a posteriori truth' that generation is normally reproduction, that animal offspring (occasional monstrous births aside) always belong to the same species as their two parents. ${ }^{4} \mathrm{He}$ explains this by the theory that the father's sperm, which is the

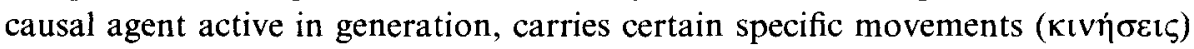
that are such as to shape the material that the mother provides in her womb into a member of the same species (and into nothing else that could survive). It does this by passing on to the offspring 'the same movement with which it too is moved' (II, $3.737 \mathrm{a} 20-1$ ). For this movement in the father's sperm (or, more accurately, as we shall see, these movements) is derived from those that are present in his blood: it is from the further 'concoction' and concentration of his blood that the sperm is produced. As the form that makes the father a human being is carried by these 
movements in his blood, it is easily understood that these same movements in the sperm are such as to make, if anything at all, another thing of the same species as the father. Now it is essential in understanding Aristotle's theory to take note of the fact that, on his account, what I have just said about the male sperm's relation to the father's blood holds equally of the female's menstrual fluid in relation to her blood. The menstrual fluid is also a 'seminal residue' ( $\sigma \pi \varepsilon \rho \mu \alpha \tau 1 \kappa o ̀ v ~ \pi \varepsilon \rho-$ $i \tau \tau \omega \mu \alpha)$, less concocted and less pure than sperm, and so not capable of generating anything, i.e. not capable of coming alive by itself or making anything else come alive (I, 20.728a 18, 26; II, 3.737a27-30; II, 7.746b26-9). ${ }^{5}$ Both these seminal fluids are derived from that element in the adult's blood that 'provides being both to the whole (animal) and to its parts', the kind of blood that Aristotle calles $\theta \rho \varepsilon \pi \tau \iota \kappa o ́ v$ (and $\sigma \pi \varepsilon \rho \mu \alpha \tau \iota \kappa o ́ v$ ) and distinguishes from the $\alpha u ̉ \xi \eta \tau \iota \kappa o ́ v$ or growth-producing kind (II, 6.744b32-8). Accordingly, in both sexes the seminal fluid contains the full range of movements that the 'nutritive' blood itself does, by which it was able to form all the bodily parts of the animal whose blood it is. It is this movement, as it occurs in the blood, that carries the 'programme' for all the specific tissues and organs that an animal of the kind in question has to have. That is why in the different, stronger form in which it occurs in the sperm, it carries this same 'programme', but in such a way as to pass it on to the foetus, as that takes shape in the mother's womb. What, however, is the function of the menstrual fluids or $\kappa \alpha \tau \alpha \mu \eta v 1 \alpha$ and their movements in this process? At this stage (in books I and II) Aristotle says little about this, but the implications of his general theory of the formation of seminal fluids by further concoction of the $\theta \rho \varepsilon \pi \tau \iota \kappa o ́ v$ or nutritive kind of blood, taken together with what little he does say about the rôle of the catamenia, make this clear enough. For Aristotle describes a progression in three distinct stages: from (1) the nutritive kind of blood to (2) the less pure, less fully concocted and 'worked up' seminal fluid of the female (cf.

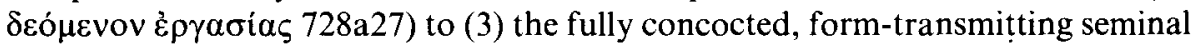
fluid of the male. The female fluid is therefore somehow intermediate between nutritive blood and honest-to-god semen, and this intermediate status that Aristotle assigns it in books I and II has clear implications about its function in generation.

First of all, it must be remembered that nutritive blood is the material from which the tissues and organs are composed. As nutriment, it is absorbed by, it turns into those tissues and organs. The way in which this blood carries the 'programme' for the tissues and organs is as matter having a principle (in fact, presumably, the $\sigma \dot{\mu} \mu \varphi v \tau o v \pi v \varepsilon \hat{v} \mu \alpha$ ) internal to it which causes it to take on the appropriate shapes and textures, etc., at the right places and times. Now one thing Aristotle says clearly and repeatedly about the catamenia is that they are the material on which the male fluid works in order to form the foetation $(=$ the

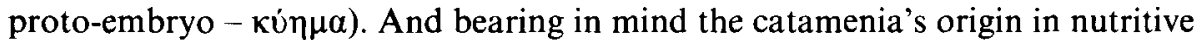
blood, one can see why just this material is what is required. Presumably, only a 
material which already was such as to be formed into organs and tissues of the types required would be suitable. For example, human semen does nothing when juxtaposed with a female dog's catamenia, because a dog's catamenia are themselves definitely disposed to be made into a dog embryo or into nothing at all organic. Hence Aristotle says (II, 3.737a23-4) that the catamenia are potentially all the bodily parts of the creature that is to be constructed out of them, but actually none of them. The menstrual fluid is potentially all those parts, because it is derived from the nutritive blood of another member of the same species, and retains from that blood just those movements that are specific for those parts (cf. 738a37-b4: the menstrual fluid is suited to be turned into a new creature of the same species, because it was already potentially material for the mother's body). Both in nutritive blood and in the catamenia these movements are movements of matter; they function as movements belonging to blood and to catamenia as matter for what is made out of them. Blood is matter for the animal itself whose blood it is; catamenia are matter for a new animal of the same species.

The seminal fluid of the male, however, has these same movements not as matter for a new animal, but as the source of its form (765b11). This means that it can make something formed from catamenia of the appropriate kind actually come alive, i.e., come to possess an independent source of its own self-regulation, including most crucially the source of its own capacity to make its own nutritive blood (also its own auxetic blood). ${ }^{6}$ The movements within the new creature's blood that are the physical realization of this capacity are given to it by the father, not by the mother, even though if the catamenia contributed by the mother did not have, as matter, the appropriate movements, the father using the instrument of his seminal fluid could not have caused it to come alive and so to come to possess that capacity.

\section{Sexual differentiation: mastery and being mastered}

So far I have limited myself to summarizing Aristotle's theory of reproduction as this is presented in the first two books of the GA. I have said nothing about particular or individual vs. merely species-specific forms, because all that Aristotle is wanting to explain in these books is why offspring belong to the same species as their parents. It is only when in book IV he attempts to give detailed explanations of the processes by which female births and inherited resemblances to parents and grandparents occur that he reaches a level of fact to which this distinction might be relevant. I turn now to consider Aristotle's account of those processes.

Book IV opens by proposing for investigation (763b25ff.) the question how sexual differentiation comes about. When, however, after discussing the views of some of his predecessors on this question, Aristotle presents his own account ( $765 \mathrm{~b} 6$ to the end of chapter 1) he invokes principles that, as he remarks at the 


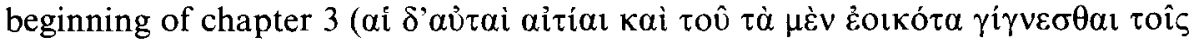

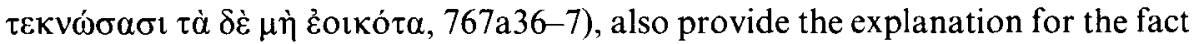
that some offspring resemble their fathers or their fathers' (male) ancestors, others their mothers or their mothers' (female) ancestors, either in overall structure and constitution and/or in that of certain bodily parts, while yet others show no particular resemblance to their forebears at all (767a36-b5). ${ }^{7}$ And once he has discussed and offered his own explanation of the phenomena of inheritance, he summarizes his results by claiming that he has revealed a common cause for sexual differentiation together with these varied facts of inheritance (769a1-6). In order to understand fully what this common cause is, we need to begin by considering the passage of IV, 1 where it is first introduced, in connection (so far) only with sexual differentiation.

At 766a10-16 Aristotle lists some principles on which he says sexual differentiation depends, of which, however, only the last seems to play any significant rôle in the explanation he goes on to provide. This last principle runs as follows (a14-16): 'Given that destruction (of a thing) is into (its) opposite, necessarily

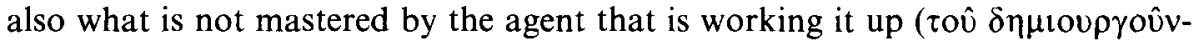
$\tau \circ \zeta)$ changes into the opposite condition'. Applied to the case of generation this means that if the male fluid and its movements fail to master the catamenial materials on which they are working to form the offspring, these materials will change (from being the male that they would have become if the male fluid had mastered them) to being the opposite of a male, viz. a female. What, however, is the cause of this failure by the male fluid to master the female? What in the nature of these fluids and the action of the one and reaction of the other causes this change in the materials? Aristotle gives a detailed answer to these questions only in chapter 3. There he introduces, for the first time in the whole treatise, (a) a differential account of the various movements that are to be found actually and potentially in the male's fluid, and (b) an explicit rôle for somehow corresponding movements in the female's fluid. Ultimately we will have to look closely at this account of the several male and female movements and their interactions in order to understand what Aristotle thinks causes this change. But already in chapter 1 two important points are clear.

First, the rôle of the female fluid remains, as in book II, wholly a rôle as matter. This is made explicit at 766b12-14, which (abstracting from textual difficulties which do not affect the main point) clearly says that it is only the male fluid that possesses a principle capable of setting in motion and shaping the female fluid into a foetus; the female's fluid is matter only. So when Aristotle says the male's

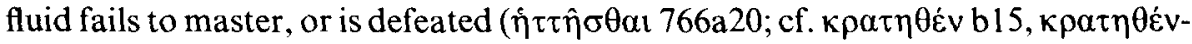
$\tau o \varsigma$ 768a34) in its efforts to master these materials, and so the materials are shaped into a female, he does not mean that some independent active, generative activity of the female materials takes over. The movements in the female materials are not a new, second set of movements, parallel to the movements in 
the male's fluid, that directly shape the foetus' bodily parts, as it were by default. Both before and after his discussion in IV of female births and inherited resemblances to ancestors Aristotle repeatedly emphasizes that only the male, through the movements in his semen, is capable in any way at all of fashioning ( $\delta \eta \mu$ ioup $\gamma \varepsilon \hat{\imath} v)$ the materials provided by the female into a new animal (I, $22.730 \mathrm{~b} 4-32 ; \mathrm{II}, 4.738 \mathrm{~b} 12-15,20-3 ; \mathrm{IV}, 4.771 \mathrm{~b} 21-4,772 \mathrm{~b} 31-3)$, and three times in the course of this discussion he characterizes the male, by contrast with the female, as the $\delta \eta \mu t o u \rho \gamma o \hat{v}(766 \mathrm{a} 15,767 \mathrm{a} 19,768 \mathrm{a} 16)$. So whatever the rôle of the female fluid's movements may be, it is not they, but the movements of the semen, that impose on the embryo its female soul and those specific movements in its body that are its soul's physical realization and that make it develop as a female.

Secondly, we already have in chapter 1 an important indication of what happens that causes the change of sex. In the passage already cited where he states his general principle about materials that are not mastered, Aristotle speaks, naturally enough (at 766a15-16) of these materials themselves changing into the opposite (of what they would have changed into if mastery had been

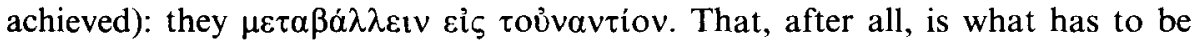
explained. But at 766b15-16, immediately after saying the female fluid is matter only and only the male's fluid is active and formative, he says this change in the materials is preceded and caused by a change in the male fluid itself: "so when it (the male fluid) has the mastery, it takes it (the female matter) over to itself, but when it is mastered, it (still the male fluid) changes to the opposite or else to

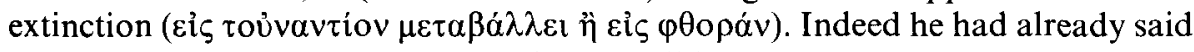
this at 766a 18-21, where however it is possible not to catch the point. For the subject of $\mu \varepsilon \tau \alpha \beta \alpha \dot{\alpha} \lambda \varepsilon \mathrm{l} v$ there could, by a remote possibility, be the materials that are the understood object of the verb å $\gamma \alpha \gamma_{\eta} 1$ in the previous clause (that is how Peck renders the lines) though by the rules of Greek grammar it ought to be the male $\dot{\alpha} \rho \chi \eta \dot{\eta}$, the subject of $\dot{\alpha} \gamma \alpha \hat{\gamma} \eta 1 .{ }^{8}$ But at $766 \mathrm{bl}-16$ this meaning is unmistakable: the defeat of the male fluid by the female fluid means that the male fluid itself in its working up of the materials is affected in such a way that it turns them into a female (and see 767b22-3: the male movements bring about, $\pi$ oteîv, this deficiency in the offspring). That is what it must mean to say that the male fluid 'changes to the opposite' (on this, see further below): it changes so as to do the opposite of what it would otherwise have done.

\section{Actual and potential movements in the semen}

For the elaboration of this theory we have to turn to chapter 3. So far Aristotle has only said that sometimes the male fluid (or its movements - at 767b18-20 he says that it comes to the same thing whichever of these one says) fails to master the female fluid that serves as original matter for the foetus, and that when this happens a female birth results. This, however, as he now points out, is an 
over-general remark. For distinctions can be made among the movements of the sperm, and it is only when certain of these movements are mastered that a female birth results. There are, first of all, its actual movements, and then some that it has only potentially $(767 \mathrm{~b} 35-37,768 \mathrm{a} 12)$ : I will explain what this distinction comes to in a moment. Secondly, both the actual and the potential movements can be divided into movements at different levels. In explaining the different levels of the actual movements, Aristotle says the following.

The sperm of any individual male animal, say Coriscus or Socrates, has movements that belong to it (1) as movements of this particular individual qua father, (2) as movements of a male, (3) as movements of a human being and (4) as movements of an animal $(767 \mathrm{~b} 25-32 ; 768 \mathrm{a} 12-13$ says these are actual movements). So in the case of a female birth, it is not the movements of the father's sperm, in general, that get mastered, but more precisely, those belonging to it as (2) movements of a male. It may happen that these movements are mastered (so that a female birth results) while nonetheless (1) the movements it has as this particular individual qua father are not. When that happens, a female offspring results, but one resembling the father. In accordance with the general principle enunciated in chapter 1, when the father's fluid fails to master the mother's with respect to its movements (2), the material being worked on 'goes over' ( $\dot{\varepsilon} \xi \hat{i} \sigma \tau \alpha-$ $\tau \alpha \mathrm{l})$ to the opposite, i.e. in this case, to being a female instead of a male (768a2-7) because, not achieving mastery, the father's fluid 'makes it deficient in that faculty in respect of which it failed to gain mastery' (767b22-3). But since the sperm masters the material with respect to the movements (1), there is no 'going over' to an opposite in the relevant respect, and so we get an offspring (a female one) resembling the father.

Likewise, as Aristotle says is the more usual thing, it can happen that the sperm is defeated simultaneously with respect to both movements (1) and (2). The result is that it makes a female resembling her mother (768a24-6) - resemblance to her mother being the opposite of that resemblance to her father which is prevented when the movements (1) are defeated. By distinguishing movements (1) and (2) and allowing that the male fluid can achieve mastery, or not, with respect to these movements independently of one another, Aristotle can explain both how female births occur, and how a female may resemble either her mother or her father. Exactly similarly, he can also explain how a male child may resemble his mother, rather than his father: because the movements (1) are defeated he resembles his mother, the opposite of the resemblance to his father that the mastery of the movements (1) would have caused.

Before pursuing further elaborations, let us pause to note one crucial point. By saying that there are actually in any male animal's sperm movements belonging to it as that individual qua father Aristotle commits himself to at least the relative particularity of that animal's form. It is through the movements in its sperm, the same movements that were in its blood and conveyed its form to its own matter, 
that an animal conveys form to the offspring, and if these movements include ones that belong to it as an individual father (whatever exactly the extent of the individual features in question turns out to be), then the father's form is not one that could be shared by all other animals of the same species, or even all the males. Aristotle already makes this clear in book IV chapter 1, when he says that if all goes well the father, using the instrument of his sperm, brings the female

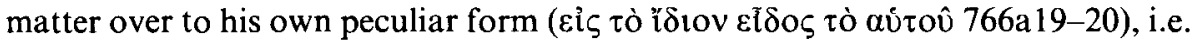
to possessing the capacity and tendency, as an independent living thing, to develop in such a way as to have those same features, whichever they are, that characterize the father as an individual and belong to him qua having that form.

So far I have discussed only the actual movements in the sperm. But there are potential ones as well, Aristotle says. First of all, an animal's sperm has potentially the movements of its $\pi$ ó $\gamma$ ovor, i.e. its father, its father's father and other male ancestors in the male line $(767 \mathrm{~b} 37,768 \mathrm{a} 11,16-18)$. It has these as potentialities of its movements (1), the movements that it possesses as being the sperm of this individual qua father. These potentialities can be realized when the sperm nonetheless achieves mastery with respect to the movements (1), and in fact only then. In that case one gets an offspring (whether male or female: sexual differentiation, as we have seen, is determined solely by whether mastery is achieved with respect to movements (2)) resembling not the father, but the father's father, or the father's father's father (and so on backward). This depends upon the phenomenon that Aristotle describes (first at 768a15) as the $\lambda \dot{\sigma} \sigma \mathrm{l} \varsigma$, the

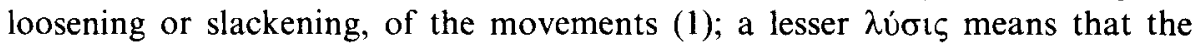
offspring comes to resemble an ancestor nearer the father, a greater one means resemblance to a more distant ancestor in this series $(768 \mathrm{~b} 9-10)$

But Aristotle seems to say that a male animal's sperm has potentially a second set of movements. At 768 al4 he says it has potentially the movements of the female, by which I believe he refers to the mother of the prospective offspring. ${ }^{9}$ That is, the sperm has in some sort of potential way the movements of the menstrual fluid of the female with which the male copulates. Now, as he goes on to say, the movements of the female animal's seminal fluid that belong to her fluid as that individual mother (i.e. its movements (1)) can also suffer loosening or slackening, just as the male's movements (1) can. ${ }^{10}$ The result is parallel to what happens in the case of the slackening of the male's movements (1). When, but only when, the male's movements (1) are mastered (or, equivalently, fail to gain the mastery), instead of an offspring (whether male or female) resembling the mother being produced, it can happen that we get an offspring resembling the mother's mother, or the mother's mother's mother, instead. Here one gets a combination of both of the two basic processes that Aristotle postulates. First, the female fluid acts on the male fluid's movements (1) and defeats them so that they $\dot{\varepsilon} \xi i \sigma \tau \alpha \nu \tau \alpha 1$, depart from their own nature, and therefore make an offspring resembling not himself but the opposite of himself. But now, there is in addition a 
$\lambda \dot{\sigma} \sigma \varsigma \varsigma$ in the victorious female fluid, and so the potentiality in the male's sperm to make an offspring like the mother's mother (instead of like her) gets actualized. That is, it appears, Aristotle attributes to the male fluid, somehow in potentiality, all the movements that are in the female parent's seminal fluid - both those characteristic of her as an individual parent and those movements of all her female ancestors that she herself carries only potentially.

Now this is not as strange an idea as it may seem on first presentation. As we will see shortly it has a deep rationale in Aristotle's theory of the rôle of the male as what alone fashions the offspring and gives it its soul or form. Moreover, it can be defended on the basis of general considerations about any process of fashioning something, whether by art or by nature. There is nothing outlandish or extravagant here at all, once Aristotle's idea is fully and properly understood.

\section{$\mathrm{V}$ Female movements in catamenia and semen}

But first I want to show through a detailed consideration of the text of $G A$ IV, 3 that it really is Aristotle's view that the male animal's semen possesses somehow in potentiality the movements of the prospective mother of its offspring. In the penultimate paragraph above I cited $768 \mathrm{a} 14$ as explicitly affirming this view, but we will need to consider as a whole the long opening paragraph of the chapter (to 768a21), in which Aristotle formally sets out all the fundamental elements of his theory, this one included. The sentence at 768al1-14 reads: 'Some of the movements (in the seminal fluid) are present in actuality, others in potentiality: in actuality, those of the male parent and of the universal, such as a human being and an animal; in potentiality, those of the female and of the ancestors.' Now (I will return to this point below) the preceding context makes it overwhelmingly likely that the seminal fluid whose actual and potential movements Aristotle here means to be talking about is the male's fluid - the fluid that shapes and fashions the embryo, and that has clearly been the only subject of his discussion in the chapter up to this point. (That is why Peck does not go beyond what the Greek justifies when he translates 'Some of the movements...are present in < the semen $>$ in actuality...). " If so, as I have claimed, Aristotle here explicitly states that the semen has, as a potentiality, the movements of the female, evidently (see n.9 above) meaning those of the mother - the ones that, when actualized, will fashion an offspring resembling the mother or one of her ancestors. On the other hand, as I have also said, Aristotle clearly does introduce in this chapter, for the first time explicitly anywhere in the treatise, movements in the menstrual fluid that somehow correspond to the movements of the semen (though he continues to hold that only the male's movements are such as to fashion, shape and constitute the offspring). Indeed he does this only four lines below (768a18-21), saying that just as the male parent's movements, when they relapse, relapse first into those of his father, or if not, into those of his grandfather, so the mother's 
relapse into those of her mother, or if not into those of her grandmother. Perhaps then he already has this parallel between male and female movements in mind in what precedes. In that case one might suggest that the fluid whose movements Aristotle means to be discussing at 768a 11-14 is not the male fluid only, as I have taken it, but seminal fluid in general - both the male's and the female's, together. Perhaps, then, in speaking of 'the movements of the female' Aristotle here speaks not of movements even only potentially in the male fluid, but simply of the movements in the menstrual fluid itself.

On this suggestion, he will be saying that some movements in the generative fluids (in general) are present actually, others potentially only: actually present (viz. in the male's fluid) are the movements of the male parent and the universals, a human being and an animal, but potentially present (viz. in the female's fluid) are all those of the mother - those it has as movements of this particular individual qua mother, and as movements of a female, a human being and an animal - and also (viz. in both fluids) those of the respective ancestors. This, however, makes little sense. (i) Exactly the same ground for saying, as Aristotle already explicitly did at $767 \mathrm{~b} 35-7$, that the movements of the male parent as that parent, a male, a human being and an animal are present in actuality in his semen, apply also to the corresponding movements of the female. So what possible reason could Aristotle have for saying that though the male's movements are present in actuality, the corresponding ones of the female are only there in potentiality? (ii) In any event, it is quite clear what the contrast between actuality and potentiality comes to in its present application. It is first introduced at $767 \mathrm{~b} 35-7$, where the movements of his ancestors are said to be present in a male's semen potentially, by contrast with those actual ones belonging to it as himself, a male, etc. The thought clearly is that the potential ones are underlying movements that become active when, as with the postulated phenomenon of $\lambda u \sigma ı \zeta$, the normally active ones give way. And that is certainly how it is to be taken in reference to the movements of the ancestors mentioned at the end of our sentence. But if in the female's fluid the movements of her ancestors are in this sense; merely potential, that must be by contrast with the movements they replace

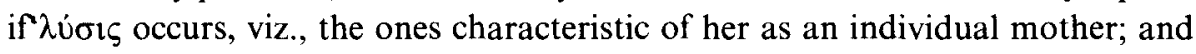
these ought therefore to be actual movements of the fluid, not a second set of potential ones instead, as they become on this interpretation of the sentence. One might try to find some other use of the word 'potentially', according to which Aristotle might plausibly have thought that even the movements belonging to a woman's menstrual fluid as that individual are present in it only potentially. ${ }^{12}$ But that would require taking the single word $\delta v v \alpha \mu \varepsilon \varepsilon$ at 768 a $13-14$ in two different senses - one for the movements 'of the female' and one for those 'of the ancestors'; and one of these senses would have no warrant at all in the evidently parallel uses of the term elsewhere in this chapter. It is impossible, then, to make 
good sense of this sentence on the supposition that in it Aristotle is discussing movements in both the generation fluids.

In any event, the context makes it clear that at 768a11-14 Aristotle is referring only to movements in the male's fluid, and that explicit reference to movements in the female fluid only occurs for the first time just afterwards, at 768a 19-21. In chapter 1, as I have explained, Aristotle introduces the central idea on which he will ground his detailed explanations - the idea that the male, active, fashioning agent in generation can nonetheless fail to master the female, passsive, material element (or, equivalently, be defeated by it). The reason he gives (at 766a19) for this defeat is that the semen is deficient in heat and so cannot concoct the catamenia to such an extent as to make them turn into another male (and, it is implied, one like the father, a19-21). In the next chapter he explains in more detail that success or failure in mastery depends really on the $\sigma v \mu \mu \varepsilon \tau \rho i \alpha$ (balance, proportion) or its absence between the semen and the menstrual fluid (767a15ff.). The heat of the semen must be in the right proportion to the moistness (and cold) of the menstrual fluid if there is to be any 'setting' of an embryo at all. If the particular semen is too hot for the given catamenia, it will just boil them away and dry them up; if not hot enough no congealing will take place at all. And likewise the exact proportions in heat and wetness of the two seminal fluids will be responsible for whether a male or a female is produced. Both his talk of the semen as sometimes mastering but sometimes being mastered by the catamenia, and these comments on the need for 'symmetry' between the two fluids, make it clear already in chapters 1 and 2 that Aristotle is going to assign an important rôle to the female fluid in determining the sex and (we may add by anticipation) the inherited resemblances of the offspring. But although he has spoken repeatedly and from very early on in the treatise about generative movements in the semen he has not yet openly mentioned movements in the menstrual fluid at all, much less any rôle they might play in this connection. Indeed, his talk of a $\sigma \cup \mu \mu \varepsilon \tau \rho i \alpha$ in the fluids' heat and wetness rather discourages the reader from thinking of corresponding, and somehow themselves operative, symmetrical movements on the female side: wetness, unlike heat, certainly does not connote movement in Aristotle's physical theory. It cannot be emphasized too strongly that, however much the theoretical basis for them has already been laid in book II, no actual mention of movements in the catamenia, much less of any rôle for them in sex-determination and inherited bodily characteristics, has occurred before $G A$ IV, 3 .

Aristotle initiates the exposition of his own theory in $G A$ IV, 3 by reminding the reader of the two principal things he has said already about the causes of female births. It is possible, he says $(767 \mathrm{~b} 10-13)$, for the male sometimes not to master the female fluid, with a resulting female birth, through youth or old age or some such cause - youth and old age were mentioned at the beginning of chapter 2 , $766 \mathrm{~b} 28-31$, as being responsible for those deficiencies in the heat of the semen 
that at $766 \mathrm{a} 19$ he said explained its failure to concoct the catamenia sufficiently and so to 'master' them. Thus he begins by continuing to focus exclusively on the semen and defects in it that lead to its failure to produce a male offspring. 'For,' he says (767bl5-18), "when the spermatic residue [viz, the semen] ${ }^{13}$ in the catamenia is well-concocted [and so sufficiently hot] the movement of the male will make the [embryo's] shape like his own.' He then makes the important generalizing remark $I$ have quoted already, that when the semen fails to master the female fluid it is nonetheless the semen that makes the embryo have a 'deficiency' in precisely the respect that is controlled by the 'capacity' in which it failed to master it - the semen fashions the offspring so that it is a female, or resembles its mother. He goes on to detail various 'capacities' of the semen (767b23-35), adding at b357 that in addition to actual movements from its capacities for the individual characteristics of the father, a male, a human being, and an animal, the semen has present in it in a potential way the movements of his ancestors. There is no reference yet to movements in the catamenia, nor has Aristotle yet even opened up the theoretical space into which they might be fitted. After all, he posed the problem he is now solving in terms of how the semen produces the effects it is seen to produce ( $\pi$ oı $\tilde{\sigma \varepsilon \varepsilon l}, 767 \mathrm{bl}, 21 \pi 01 \varepsilon \tilde{\mathbf{i}} 23$ ), and it is only natural that he has gone on to explain them by telling us about the semen - about 'capacities' and movements in it, such that it produces one result if they achieve mastery and the other if they do not. Up to this point it is exclusively the semen's capacities and movements that he has told us anything about.

The mention of the male's ancestors at $767 \mathrm{~b} 37$ introduces the concept of potential movements, and with it the second of Aristotle's two postulated processes, that of the loosening or slackening of the movem. ats. For the movements of the ancestors, which are potential movements, get progressively made actual (first those of the grandparent, then those of the great-grandparent, and so on) as the movements that are in the father's semen as that individual parent themselves undergo a lesser or a greater slackening or loosening (cf. 768 a 16-18, b8-10). It is only when he comes round to explaining this slackening of movements and consequent resemblance to ancestors, instead of to parents, that Aristotle opens up the theoretical space into which movements in the female matter might be placed. 'And' he says (768a9-11), 'similarly for the faculties next in line. For it [sc. the matter from which the offspring is being made] always tends to go over to that one of the ancestors that stands next in line, both on the father's side and on the mother's.' In order to explain the offspring's 'going over' to the mother's ancestors Aristotle proceeds to assign an explicit rôle to movements in the female residue. But first, in accordance with his general theory and in continuation of what he has been saying immediately before (768a2-9), where he has repeated his account of how the semen fashions the offspring into a female and/or a person resembling the mother, he points out that the semen itself contains, in potentiality if not actuality, all the movements that are necessary to it 
if it is to do all these jobs - the movements of the female, along with those of his own and her ancestors. This is our sentence at 768a11-14, quoted above: 'Some of the movements (in the seminal fluid) are present in actuality, others in potentiality: in actuality, those of the male parent and of the universal, such as a human being and an animal; in potentiality, those of the female and of the ancestors.' 14 Only then does he go on, in giving details of how resemblance to ancestors on either side is produced, to introduce into his explanation movements in the female residue itself.

So then, when it [sc. the matter from which the offspring is being made] departs from its own nature, it changes over into the opposites. But the movements that are fashioning [the offspring] slacken into the nearby movements, for example if the movement of the male parent slackens, it goes over by the smallest variation to the movement of his father, or in the second place to that of his grandfather. And in this way too on the side of the females, ${ }^{15}$ the movement of the female parent goes over to that of her mother, or if not to that, then to the movement of her grandmother. And similarly also for the more distant ancestors.

(768a 14-21)

Aristotle does not immediately explain (but see 768b15-25, and my comments below, pp. 30ff.) why he needs both the potential movements in the semen and these corresponding ones in the catamenia, but the reason is clear enough. On his view, reaffirmed in this chapter at $768 \mathrm{~b} 16$ and $25-7$, the semen is the active, formative agent, the catamenia the passive material in the generative process. As being the material from which the offspring is constructed the catamenia cannot initiate any of the movements that fashion the offspring, or determine directly the course which any of these movements take. Aristotle points out two ways in which the catamenia can nonetheless affect these processes by affecting the semen itself, which is the source of them. First (see 768b25-7) it can be too cold or too great in amount for the semen to work it up fully according to its natural tendencies (i.e. it can cause the semen to fail to master it). One way this can happen is for the semen to be unable to make the offspring resemble the male whose semen it is, and then, as Aristotle has already explained, it makes the material go over to resembling the mother's side of the family. And here the second way Aristotle distinguishes in which the catamenia can affect the semen and its operations comes into play. Since any agent in acting on materials is itself reciprocally affected by them, the semen can be brought, in working on the catamenia, to be affected by them in such a way that its movements slacken, from being ones that would produce a resemblance to the mother to being ones that produce a resemblance to her mother or another of her ancestors. The catamenia do this when their own movements (1) slacken into movements of the forebear in question; that alters the character of the catamenia as they reciprocally affect the 
semen, so that they induce its movements to slacken in just the way required. That is to say that one gets here a combination of both the two processes Aristotle postulates. The semen first fails to master the female fluid, which therefore departs from its nature and is made to resemble not the father (as would be more natural) but the mother. But secondly (and this is where movements in the female fluid enter the theory explicitly) the movements of the female fluid themselves slacken, reciprocally affecting the semen as it acts on it, so that its potentiality to produce in the embryo movements for the mother's ancestors (instead for the mother herself) comes into play.

Now the sentence at 768a11-14 is the only explicit indication in his text that Aristotle postulated movements somehow potentially present in a male's fluid capable of imposing on an embryo bodily resemblances to its mother's side of the family. Regrettably, he does not pause to explain how we are to understand this 'potential' presence (and how we are to relate it to the 'potential' presence of the movements for resemblances to the male's own ancestors). Two possibilities suggest themselves. If one bears in mind simply the theoretical need that Aristotle has for such potential movements, the following, relatively vague conception may recommend itself. If there are to be resemblances to the mother or to any of her ancestors, then the embryo's own soul, through the formative movements in the blood its heart makes, must produce and maintain these. The material from which the embryo is itself originally constituted and by which it is nourished so long as it is in the womb, being provided by the mother, already carries, either actually or potentially (as an inheritance from her ancestors, through her own mother), all those movements - as movements of matter, however, not yet as formal movements (i.e. movements of the embryo's form). What the father's semen and its movements need to do, therefore, is selectively to elevate whichever of the movements belonging to the material provided by the mother will carry such resemblances to her side of the family as there are going to be, from being movements of matter to being formal movements in the matter. This suggests that we think of the potential presence of the female movements simply as the potentiality in a male's sperm to do this job: the power to work on the materials provided by the mother so as to elevate to the level of formal movements material movements already actually there (because they carried the instructions for the formation of her own bodily parts) or potentially present (as underlying traces inherited from her ancestors). On this conception, the semen would be said to have these movements potentially, just in virtue of the fact that it is capable of making the embryo have them as movements of its form - despite the fact that the semen does not impose them, in the sense of transferring from itself movements already actually or virtually existing in it, so much as simply work to strengthen movements provided by the mother in the catamenia.

On the other hand, Aristotle's mentioning together, and apparently without distinction, potential movements 'of the female and of the (male's) ancestors' 
may suggest some more substantial way the semen might possess these movements. For it seems reasonable to think that an animal's semen has movements for his own ancestors (in respects in which he does not himself resemble them) in some underlying, non-actual, but nonetheless physically realized way. So perhaps Aristotle is thinking that there is in the semen some physically realized representation of the movements of the females he can copulate successfully with (and their ancestors). Obviously this will still be something vague and general, since it must cover so many distinct possibilities. But on this second conception, much more readily than on the first, it will be natural to speak of a male as having in a potential way the very movements by which the mother's blood and her catamenia are actually moved (and those that are potentially in them as inheritances from her ancestors) - and, as we have seen, that is how Aristotle puts his theory at 768a14. On this second conception, he will still be saying that the semen elevates the movements of the catamenia to the level of movements of the embryo's form, but he will be postulating some sort of physically realized representation of these movements in the semen as what makes it possible for it to do this. Aristotle's text does not allow us to decide between these two ways of construing the 'potential' presence of the female movements in the semen. ${ }^{16}$ In what follows, one should bear them both equally in mind.

\section{Potential movements and their actualization}

Thus, subject to clarification about how we are to conceive his own and the mother's ancestors' movements being potentially in the father's sperm in the first place, Aristotle has explained offspring, both male and female, resembling not the father or the mother, but any of his male ancestors in the male line or any of her female ancestors in the female line. Conspicuously, he has not yet explained, or even clearly allowed the possibility of, offspring of either sex resembling their father's mother or their mother's father, or any other female on the father's side or male on the mother's. I assume Aristotle intended to allow for these resemblances too, perhaps by simple extensions of his theory as so far expounded; but as I read him he does not mention such resemblances in this chapter or indicate how he would explain them.

We must take note of one last elaboration of the theory. So far I have spoken only of an offspring's inherited resemblance as a whole and overall to some single one of its forebears. But, as of course their nature as residues derived from nutritive blood already implies, both the male and the female seminal fluids contain movements specific for each of the bodily tissues and organs, and specific for them with whatever special features of form and structure the parents' blood was so 'programmed' to produce and maintain in them. (Obviously, though Aristotle does not say this explicitly, what are in question here are features of the movements (1).) So similarly for the potential movements in the fluids that, when 
the actual movements slacken, take over and in the way I have explained, produce resemblances in the offspring to the parents' parents and grandparents: potentially, movements specific for each of the tissues and organs of each of these forebears are also present in the seminal fluids. Accordingly (768bl-5) Aristotle can claim that his theory provides an easy explanation for all possible combinations of partial resemblances between offspring and either or both parents and any of these ancestors you like. Mastery and being mastered, and slackening of movements, can be partial and selective at every level.

Aristotle will not, of course, have given a complete explanation of these or any of the other phenomena of inheritance until he has said (i) what it is for a seminal fluid to have movements potentially and (ii) how the male's sperm, in particular, comes to have the movements potentially that Aristotle says it has. The answer to this second question will be particularly difficult, of course, for the movements of the female with whom the male happens at the moment to be copulating. For, as I have pointed out, Aristotle claims the male's sperm has in some sort of potential way the movements (1) of any female with whom it mates successfully. How does an animal's sperm come to have those movements, even potentially?

The answer to my first question is quite easy. What it is for a seminal fluid to have some movement potentially is for it to have that movement in such a way that an offspring it generates, or that is generated from it, comes as a result of the generative activity, to have it actually in the blood that its heart makes. Or, to put the same point one stage further back in the process of explanation, it is to have those movements in such a way that the activity of generation makes the movements in the offspring's body that depend on and express its form be in actuality the same as those merely potential movements in the seminal fluids. Aristotle obviously cannot think that under certain conditions the seminal fluid of an animal, while remaining that seminal fluid, comes itself actually to be moved by the movements specific for its parents' or grandparents' tissues and organs in those respects where the animal's own tissues and organs are significantly different. An animal's seminal fluid can only actually have whatever movements were actual in its nutritive blood, and these, ex hypothesi, were not actual there. The actualization of these potentialities of movement cannot then be found in the semen or the catamenia themselves. But since the whole natural purpose of seminal fluid is to be the instrument or the material for reproduction, it seems acceptable to think of the realization of the potentials in those fluids as taking place outside them, in the offspring that comes into being. Anyhow, that is what Aristotle clearly intends.

For our inquiry this fact has particularly significant implications in the case of the male fluid. The female fluid has potentially the movements of her ancestors just as the male's does of his. But on Aristotle's theory the male fluid is the sole source, in the sense of the moving cause, of the offspring's form and so of the movements in its body (in its heart, in the first instance, and derivatively from 
that in the blood that its heart manufactures) that express that form and convey it to its material constitution. When, therefore, Aristotle says that the male's sperm contains potentially both all the movements of its male forebears in the male line, and all the movements of the female it copulates with, including those of all her corresponding forebears, he is saying what he must say if he is to explain the phenomena about inherited characteristics while sticking to his basic theory of reproduction, as he has worked that out in $G A$ I and II. If the offspring's metabolism regulates it in such a way as to fashion and maintain certain specific shapes and organizations for its tissues and organs, these must be due to its form (unless there is some special other explanation of how this regularity is maintained). But on Aristotle's theory the male parent, and only it, causes, in the sense of being a moving, creative, shaping cause, the offspring to have just that form, whatever it turns out to be like, that it has. If some of what the offspring's form does is to make it like its mother and her family then the father's sperm, the instrument he uses to move, fashion and shape the matter so as to have that form, simply has to have, in some way or other, those movements potentially in it. Otherwise it could not engender in the offspring all the movements that express and convey the offspring's form, and so we would have to look for a separate second source of some aspects of the offspring's form. It is clear, then, that so far from abandoning or incoherently contradicting his theory of reproduction by invoking movements in the female fluid to explain some of what happens, Aristotle goes to great lengths in $G A$ IV, 3 to maintain it. By assigning the mother's movements to the father at the level of potentiality he insists, as he thinks one must, on the male's exclusive rôle as source of the offspring's form. Accordingly, in his theory of inherited resemblances Aristotle carefully denies any formative, active, creative rôle on the part of the female in bringing this form into existence. The contribution which it might appear she makes to that form, Aristotle insists, the father makes instead.

It should now be relatively easy to answer my second question, about how the male's sperm comes to have, even potentially, all these movements, both those of its male forebears and those of the prospective offspring's mother and her female forebears. About its having his forebears' movements I can be brief. (The explanation is parallel for a female's seminal fluid having in potentiality her female forebears' movements.) These the animal simply inherits. My form and the movements which express it in me derive from my father's form and the movements that express his in him, and his from his father, and so on backwards. There should be no difficulty, then, in seeing that all those movements may be retained in my sperm, the ones that are not there in actuality being retained in potentiality.

How the prospective mother's movements get into the sperm of the male she copulates with in whatever way they do, is another question. We can best approach it by seeing how Aristotle accounts for the realization of these supposed 
potentialities. He appeals here to two connected ways in which in general when agents act on materials in an effort to shape and work them up, they in their turn are or may be affected by the materials (768bl5-36; cf. 766a15-16, 18-21). First (b15-25) he explains the relapsing ( $\lambda \dot{\varepsilon} \sigma \theta \alpha \imath$ ) of the male's movements ${ }^{17}$ - into the movements of his own forebears, but also, as we have seen, into movements productive of resemblances to the mother and her forebears. This is a special case of the general phenomenon, discussed in de Gen. et Corr. I, 7.324a24ff. to which he here (b23-4) refers, of an agent's being reciprocally affected by the patient on which it acts: 'a thing which cuts gets blunted by the thing being cut, a thing which heats gets cooled by the thing being heated,... what pushes gets pushed in a way in return, what squeezes is squeezed back' (bl6-20). These examples (especially the first) clearly suggest that Aristotle is thinking here primarily of such intermediate agents as the tools a primary agent uses to bring about his effects. And that is appropriate, since on his theory the semen is the instrument the father uses to set and shape the foetus, and it is something that sometimes happens to the semen, namely the $\lambda$ úois of its movements, that he is trying to explain. Failure of mastery he explains (b25-36) as a case of an agent's being too weak or the materials being too formidable in some relevant respect for the agent to impose on them exactly what, given that it is that kind of agent, it has in it to do on suchlike materials - as for example happens with athletes in training, whose unusually large intake of food (he says, b29-33) overstrains their digestive systems' power to assimilate the nutrient and distribute it so as to maintain their normal proportions, with the resulting outsized and sometimes grotesquely misshapen musculature, etc., characteristic of athletes. Here, evidently and again appropriately, the semen's agency is being compared, if to that of a tool at all, at any rate to one (unlike, say, a doctor's knife) with its own inherent power to affect and shape the product.

Now for each of these general principles, but especially for the first, there are difficulties in understanding how Aristotle thinks its application to the semen produces the desired results. The reciprocal blunting of a knife and cooling of a hot object placed into contact with something colder than it are instances of an agent's undergoing the precisely opposite effect to what it does (both normally and in the given case) to the patient. But in $\lambda$ uors the semen is affected by the catamenia so that what it then does to them is different from what Aristotle thinks should be normal, and moreover it is not easy to see how the change it undergoes (from exercising its actual to exercising one or more of its potential movements) can be construed as due to its undergoing the opposite of what it does (either normally or in the actual case) to the catamenia. According to Aristotle's account

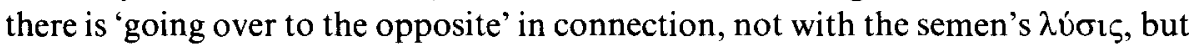
with its being defeated by the catamenia. It appears that in these analogies Aristotle has somewhat run together his two processes of the defeat of the semen's movements by the catamenia and their slackening. 
Perhaps the following analogy, a close relative of those Aristotle actually invokes, will help to resolve these difficulties, and to show why it seems to Aristotle to make good sense to attribute to the semen as potential movements the 'movements of the female'. ${ }^{18}$ Consider a sculptor working on some soft stone. It turns out that his skills are not adequate to make this particular piece of stone have exactly the degree of surface finish that the statuary's art demands: he does not possess the lightness of touch necessary to achieve a greater degree of finish without chipping stone. He might of course abandon the effort once the inadequacy of his skills becomes clear to him. But suppose he doesn't. Then whatever features of shape, surface texture etc. the resulting statue has will have been the product of his art: his art will have been the originating source, and the only originating source, of these outcomes (assuming nothing pushes his hand or falls on the statue while he is working on it that affects these features). The stone itself contributes only as matter, not as a source of any of the changes it undergoes while these outcomes are being achieved. It is not as if there is a nisus in the stone for this kind of surface texture, etc. Yet the principles of the artisan's art, as they actually exist in him in whatever way principles of art do exist actually in an artisan, do not themselves explain these deviant features of the outcome. Still, even these features are not due, even in part, to any accident: the agent is the non-accidental moving cause of them, just as much as he is of the others. He at least settles for these outcomes, even though he does not set out to achieve them or intend them; on the contrary, he is aiming at as perfect a realization of the sculptor's art as he can achieve, not this defective one that he actually achieves. The skill within him is, however, such that this is the best that in these circumstances it is capable of producing. So we are led to recognize, in addition to the actual principles of the art in him, other somehow underlying and potential ones that suit him, precisely, to be the moving cause of these deviant features. What calls these 'potential' principles into play are defects in the agent's manual abilities or resistance in the materials, or both.

The father's sperm as moving cause of the offspring's form is a parallel case. Here too we find that sometimes, through no accidental interference of another moving cause, the materials do not come to have the movements that the principles for constructing it that are actually present in the sperm dictate. It comes to have female movements and/or movements that make it like its mother, or her family. Yet it was nonetheless the sperm and not the materials themselves that put those movements there: there is no independent source of development to that end in the materials. The female seminal fluids are materials only; they make no motion toward coming alive unless and until they are moved about by the sperm. So, just as in the case of the statuary, we are justified in attributing to the sperm, somehow in potentiality, exactly those movements that would directly explain the presence of the same movements in the offspring. 
This is obviously a very weak way of having movements or other principles potentially; on either of the two ways I have suggested we might construe this potential presence. And that is all to the good. One would not want it to turn out in any more robust sense that a male's sperm has in potentiality the movements in it of the females it happens to copulate successfully with. Still, the analogy with other artisans does support this weak way of having movements potentially, and that is what Aristotle needs in order to explain this part of the phenomena. For one must bear clearly in mind that though movements specific for a female, etc. are already present in the mother's seminal fluid, they are not present in the way they must come to be present in the offspring if it is to be a female and/or resemble the mother or her family. For the latter, they must be present as movements of the form; they must be movements deriving from its soul, not from its matter. And, on Aristotle's theory, only a form can make such movements come to be. Aristotle's claim is this: because those movements are present as movements of the matter, the male's form in certain cases being reciprocally affected by them, produces the formal movements in the offspring that correspond to those movements in the matter and that make its body continue to have them after it becomes a self-regulating embryo. The formal movements imposed by the sperm enable the embryo itself to take over from its mother the capacity to maintain the existence of these movements in its material constitution.

Perhaps it is not going too far to suggest that this is Aristotle's intended explanation for how the male's sperm must have potentialities in it for a female birth and/or an offspring resembling the mother or her family, and how they get realized.

\section{Metaphysical consequences and problems}

It is clear from our study of $G A$ IV, 1 and 3 that Aristotle holds a male animal's form directly responsible for details of its offspring's internal structure and organization that lie well below the level of its specific identity as a member of the lowest animal kind to which it belongs. In his discussion there Aristotle does not say which such details he thinks the form is responsible for. Presumably that is because his purpose is simply to show that and how his theory of reproduction is able to handle the kinds of births that are actually observed: both male and female, and males and females that resemble, both as a whole and/or with respect to various single bodily parts, one or more of their parents, parents' parents, etc. One may however appeal to other parts of the treatise to obtain light on this question. Aristotle pursues the general topic of resemblances of offspring to parents at some length in discussing the panspermia theory in $\mathrm{I}, 17 \mathrm{ff}$. - the theory held by some of his predecessors that the generative fluid is drawn from all parts of the body (and from both parents). At several places he mentions detailed types of resemblance, where he might be thought to be accepting that these are 
inherited through characteristics of the generative fluids. And in v, 1-4, he discusses, among other things, the causes of differences among human beings in eye-colour, the tendency to go grey or get bald as age advances, and the colour and texture of the hair - all differences that we would count as at least partly genetic in origin. Does Aristotle, too, explain them as due to inheritance?

Aristotle cites four pieces of evidence (I, $17.721 \mathrm{bl3ff}$.) as allegedly supporting the panspermia theory. The most important of these derives from the resemblances that offspring show to their parents (b20-4). But it must be carefully borne in mind in assessing this alleged evidence and Aristotle's response to it that, as Aristotle understands his opponents' argument, the resemblances in question are of two kinds. ${ }^{19}$ First (see $\mathrm{I}, 18.723 \mathrm{b3}-9$ ), there are resemblances that any member of the species shows to any other (of the same sex): the same organs and limbs distributed in the same manner and with more or less the same physical constitution (human flesh, hair and toenails, say, as against canine). And secondly there are more specific resemblances in any of these respects to one or another of the parents in particular. Aristotle's panspermia-opponents think that resemblances of both types require to be explained by the supposition that, in general, each part of the body of each parent supplies some of the generative fluid from which the offspring derives. They find confirmation for their view in the alleged fact that mutilated parents produce offspring missing the same part $(721 \mathrm{~b} 17-20)$ and that children resemble their parents even in acquired characteristics, such as brandmarks on the father's arm that turn up also on the son's (b29-34).

Aristotle rejects this theory, of course, and he plainly does not feel obligated to accept that all the resemblances appealed to by its proponents (that brand-mark, for example) have to be explained at all as due to features of the semen (let alone by the hypothesis that some of it comes from each part of the parent's body). For example, Aristotle himself denies that children with congenitally missing limbs, whether they share the mutilation with a parent or not, ever lack these limbs because of defects in the semen that fashioned them (IV, 4.772b35-773a3; cf. I, 18.724a3-7). But equally plainly he does accept that many of the resemblances his opponents had in mind are inherited, and will accordingly have to be explained as passed on from parent to child through the action of the semen: it's just that the panspermia theory is not the right explanation of how this happens. Unfortunately, however, it is not possible to infer anything from his discussion of this theory that helps answer our question about the extent of such resemblances.

To be sure, he says clearly that resemblances between child and parent are found in anhomoeomerous parts such as face, hands and feet more than in the homoeomerous ones (tissues, etc.) (722a19-21), but this does not tell us which features of which of these parts he thinks are inheritable (for example, whether eye-colour is). Again, he objects that children resemble parents in many respects that his opponents will have to agree cannot be due to some of the semen's having been drawn from a corresponding part of the parent: voice, nails, hair, manner of 
movement, grey hair or beard (when the parent did not yet have these at the time of conception) (722a5-7) - indeed, he points out (723b30-2), a son who resembles his father tends to wear shoes that resemble his too. Given the variety of items in this list, and the nature of Aristotle's argument here, it would be hazardous to infer from these passages that he accepts even the resemblance in nails and hair between child and parents as explainable by inheritance. If one were nonetheless inclined to think he did mean to be granting his opponents that point (while denying that it could be due to some of the sperm being drawn from the parent's nails and hair), the possibility would remain open that he was granting only the general resemblance (human hair and nails, as against canine) and not a more particular resemblance to special features of the parent's nails and hair. And greyness in old age he definitely does not explain as inherited, in the sense of specifically provided for in the formative movements of the father's semen and/or the corresponding movements of the menstrual fluid; it is a side-effect of the natural deterioration in the ageing process (see $G A \mathrm{v}, 4$ ).

David Balme has, however, attributed to Aristotle the view that in a correct reproduction the offspring will be a replica of the sire', including even in nonessential details, such as eye-colour, type and colour of the hair, and so on.20 Balme seems to have been led to this interpretation by reflection on the significance of the priority for Aristotle of what I have been calling the movements (1) of the semen at $G A \mathrm{IV}, 3.767 \mathrm{~b} 26-35$. Aristotle does indeed say there that the movements the semen has from the father as that individual, rather than as a male or a human being, come first and will control the formation of the offspring if nothing untoward happens. But Aristotle characterizes these movements not simply as movements of the individual father (in general) but of him

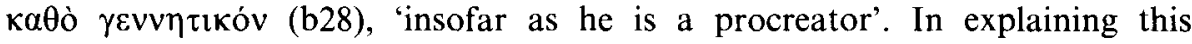
qualification he excludes from the scope of the movements "what he is incidentally, e.g. if the male parent knows his letters or is someone's neighbour' Obviously he intends to exclude also even any congenital properties that may be similarly incidental, e.g. if by some mishap in the womb the father were born with one leg shorter than the other. The semen only aims to reproduce in the offspring whatever properties of the father are relevant to his rôle as procreator, and while it is clear that this includes all his essential organs and limbs, and all their properties (even the individual ones) that are relevant to their correct functioning, there is a significant further question as to what these properties are. In general it is clear what Aristotle's answer is: whichever properties of the father's body the formative movements in his blood contain specific information for. What lies outside that, so that its presence in his body is, from this point of view, produced by the movements in the blood only incidentally or accidentally, it is not part of his procreator's rôle to pass on. This distinction, however it is worked out in detail, will determine, on Aristotle's view, in what respects the semen will see to it that the offspring resembles the father, and in what it may very well not resemble 
him, (even) if nothing untoward happens. A replica it certainly does not attempt to produce.

Does Aristotle, however, think eye-colour and the like are matters that the father's semen contains specific information for, and with respect to which it will cause a paternal resemblance in the offspring, if nothing untoward happens? If one consults Aristotle's discussion in $G A \mathrm{v}$ one can see that the answer is definitely in the negative. His explanation of eye-colour (v, 1.779a34-bl, b12-34), for example, is that it depends upon the amount of fluid that the eye happens to contain: people with more fluid in the eye than is ideal for seeing are dark-eyed (because large volumes of fluid are dark), those with less fluid than is ideal are blue-eyed (for the corresponding reason), those with just the right amount of fluid have eyes intermediate in colour. The quantity of any person's eye-liquid Aristotle treats as in effect an accident, the result of the amount of liquid that happened to be available for the semen when as moving cause it worked on that liquid to form the eye in the first place $(778 \mathrm{a} 35 \mathrm{ff}.) .^{21}$ Likewise $(\mathrm{v}, 3)$ he explains differences in the condition of the hair, and hairiness itself, as due partly to accidental differences in the character of the skin and the amount and quality of the bodily fluids, and partly to environment: he explains the Scythians' and the Thracians' straight hair by the wateriness both of their constitution and of their climate, and the Ethiopians' curly hair by the dryness of both their brains and their climate (782b33-783al).

It does not occur to him to explain any of these differences in constitution (not even these racial ones) by inheritance. Neither in connection with eye-colour nor with the hair does he anywhere employ the apparatus of mastery and being mastered and the slackening of movements that he has developed in book IV to explain characteristics inherited whether from the mother and her family or from the father and his. A sensitive reading of $G A \mathrm{v}$ shows, therefore, that Aristotle thinks the father's semen contains specific instructions for the formation in the child of an eye of the right type for human vision, but that what colour it will be is determined by accidental features of the matter that the mother happens to provide for its formation on the occasion of the conception.

It follows that Aristotle does not think that the male parent's form is responsible for biologically superficial characteristics like eye-colour, pitch of voice, and coarseness or fineness, length, quantity and natural straightness or curliness of the hair. These are material by-products, not anything the form's 'programme' contains a specification for. In our example from statuary they correspond to features that a statue has because the material it was made out of already had them too. These are accidents, not initially due to the parent's form and so not later on due to the offspring's own form, except incidentally, when that takes over from the parent responsibility for its growth and self-maintenance. 
Taken altogether, then, Aristotle's various discussions of inherited resemblances between offspring and parents imply a less than fully determinate theory about what features of any animal its form is directly responsible for. Its form is not directly, but only incidentally, responsible for secondary, superficial, biologically insignificant characteristics, such as eye-colour. But it is directly responsible not only for its having all the tissues, organs and limbs essential to a human being, but also for many individual features of the way these are found constituted and arranged in that particular animal. Roughly, these will be all those features that, as Aristotle thinks, cannot successfully be explained as due either to environmental influences or to incidental properties of the matter that goes to constitute and sustain them. The indeterminacy derives from the fact that Aristotle does not, and given the very incomplete information that research into animals had yet provided, presumably could not responsibly, draw this line at all sharply. But even with this limited degree of determinacy Aristotle's conception of animal forms in the $G A$ has clear and significant consequences for his metaphysical theory of substantial form.

As I mentioned at the outset, some have thought from reading just the Metaphysics that an Aristotelian form is a non-repeatable instance of some general specific type, differing from other instances not internally (by reference to the logos of its being) but only by the accidental historical facts about the individual object whose form it is by which we mark that individual off from others of the same species. The $G A$ makes it clear that, on the contrary, each form has in principle a full logos of its being as the form that it is that includes the specification of all those distinctive characteristics of structure and organization for which in the individual whose form it is it is directly responsible. In fact, those characteristics are not accidents at all, but precisely programmed for in the logos of the movements that the form imparts to the nutritive and auxetic blood from which the organs are originally formed and thereafter maintained. Thus Aristotelian forms are particular in that each form contains within itself the basis for its differentiation from (as well, of course, as its affiliation with) other forms of the same specific type. As Aristotle's theory of the different movements in the seminal fluids makes clear, the logos of the being of any form (say mine) when fully spelled out will contain a good deal of information (whatever is necessary and sufficient to determine that I am a human being) that is also contained in yours. But there will also be further information that determines those special ways I am a human being which mark me off from at least most other people by making me resemble my family and not theirs. Whether or not Aristotle thought these details sufficient in principle to describe me uniquely is unclear from anything he says or implies in the $G A$. But presumably he did not.

Two immediate consequences deserve emphasis. First, in the $G A$ Aristotle makes no use of and has no need at all for those species-forms - the form of a human being in general, for example, shared by all the human beings - that are 
the staple of much contemporary discussion of Aristotle's metaphysics. All the work such forms might be thought to do is already done by these more particular forms: my form makes me a human being, while also making me a human being with those particular further characteristics I inherited from my ancestors. But secondly, while such commitment to the detailed particularity of forms may seem to belong to the same movement of thought which, in the Metaphysics, at least pulls Aristotle toward a theory of forms as individual entities, one for each distinct individual substance, Aristotle's clear commitments in the $G A$ do not extend that far. The decision whether Aristotelian forms are individual entities or in effect some sort of universals will have to be made on other grounds. But if they are universals they are universals of a much lower order of generality than has been thought; and if they are individuals they are individuals differentiated from one another not only by accidental historical facts about the material object whose form they are but, much more fundamentally, by the internal character of each individual form itself. ${ }^{22}$

PRINCETON UNIVERSITY

JOHN M. COOPER

\begin{abstract}
NOTES
1. An important exception to this general rule are two papers by D. M. Balme, 'Aristotle's biology was not essentialist', Archiv für Geschichte der Philosophie 62 (1980) 1-12, and 'The snub', Ancient Philosophy 4 (1984) 1-8, now revised and reprinted in A. Gotthelf and J. G. Lennox, (eds.), Philosophical Issues in Aristotle's Biology (1987) 291-312.
\end{abstract}

2. It is a matter of indifference for my discussion what the order of composition of these works may have been.

3. See Michael Frede, 'Substance in Aristotle's Metaphysics', in his Essays in Ancient Philosophy (1987) 72-80 and his and Günther Patzig's edition, German translation and commentary on Metaphysics Z (forthcoming 1988).

4. See his Substance, Form and Psyche (1988).

5. Although, as these passages witness, Aristotle often refers to both the menstrual fluid and the semen as sperma, he also often (most notably in $G A \mathrm{I}, 17$, when raising the question whether both the male and the female contribute something that then works to structure and form the embryo) uses this word more narrowly, to refer to what does do the work of structuring the embryo (and on his view not the female fluid, but only the male, does that.)

6. But only if there is a $\sigma v \mu \mu \varepsilon \tau \rho i \alpha$, a suitable balance or 'symmetry' between its heat and movements and the wetness and quantity of the catamenia that it works upon. Aristotle emphasizes the need for this 'symmetry' as early as I, 18.723a28-31: see also 729a16-19, 743a26-34, 772a 10-22, 777b27-9 and especially 767a13-35, discussed below p. 24. As Aristotle often makes explicit in these passages (729a17, 767a17-20,772a11-12), this is a symmetry between an active factor in generation (the male) 
and a passive one (the material provided by the female). His talk of symmetry in this connection does not imply any kind of interaction between the two factors, in the sense of a joint working together by two independent but proportionately coordinated agents with a view to a common product.

7. He says also that the same principles explain monstrous births - offspring that are animals but not regular human beings at all. I do not discuss this extension of the theory.

8. In both these passages I take it that $\mu \varepsilon \tau \alpha \beta \alpha \lambda \lambda \varepsilon \varepsilon v$ is being used intransitively, as elsewhere in this context $(766 a 16,23-4,24 ; 768 a 14)$. A survey of Aristotle's usage shows that where he does use $\mu \varepsilon \tau \alpha \beta \dot{\alpha} \lambda \lambda \varepsilon \varepsilon v$ transitively the object of the verb is almost always the respect in which the thing in question changes, almost never some other person or thing on which it effects a change. (The only clear instances of this latter kind that I have found are at HA 592al5 and Poet. 1459b41.) So Aristotle's words here do not mean that the male fluid 'changes the female fuid to the opposite or to extinction'.

9. Taken out of context 'the movements of the female' might, I think, be given any of three interpretations: (1) the movements belonging to the menstrual fuid, (2) the movements (belonging to

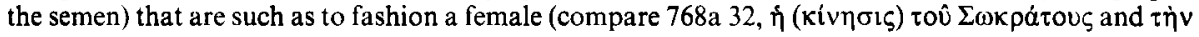

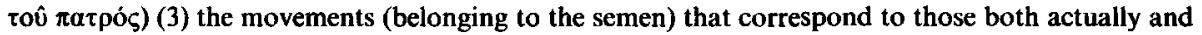
potentially present in the mother's menstrual fluid. I argue in the next two paragraphs against opting for interpretation (1) in this context. I prefer (3) to (2) because I understand Aristotle's purpose in these lines (to 768a21) to be to explain how the semen can be responsible for fashioning not just a female (as (2) would permit) but one resembling her mother or any of her mother's forebears - the movements characteristic of whom are of course in the mother's menstrual fluid either actually or potentially. But on either of these two interpretations the basic principle is the same: Aristotle attributes to the semen, as a potential movement of its own, a movement it is going to put actually into the embryo in fashioning it.

10. Since Aristotle only explicitly mentions movements in the catamenia while discussing the phenomenon he calls $\lambda \dot{\sigma} \sigma \mathrm{l}$, which only operates on movements (1), he never has occasion to attribute to the female fluid movements (2), (3) and (4). On general grounds we can infer he must suppose these other movements are present too.

11. The French translation of $P$. Louis agrees with Peck at this point.

12. One might think, as Geoffrey Lloyd has suggested to me, of Aristotle's remarks at e.g. 737a22-34, $738 \mathrm{~b} 3-4,740 \mathrm{~b} 18-20$, to the effect that the material contributed by the female is already potentially, though of course not actually, all the bodily parts that the male will fashion it into. But these remarks hardly yield a sense in which the movements in the menstrual fluid, that are in fact Aristotle's ground for saying that it is potentially all those bodily parts, are not present in it actually, but only potentially; indeed, they imply precisely the contrary.

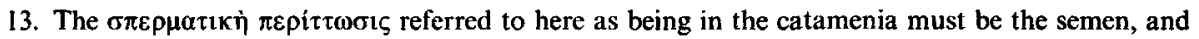
not the female fluid itself, for two reasons. (i) This sentence supplements the statement at $767 \mathrm{~b} 10-13$ just before about what causes a female birth, by stating the cause of the contrasting male birth. Since the female birth was said there to be caused by a defect in the hotness of the semen, we need a reference here to the well-concoctedness, and so hotness, of the semen as what causes the male birth. (ii) In the following sentence Aristotle makes a remark about the equivalency of speaking in such contexts of either the semen (yovin) or the movement (in it), and the relevance of that remark here is heightened by, if it does not actually require, a reference to the semen in the first part of this sentence. Read that way, Aristotle does precisely begin by speaking at $767 \mathrm{~b} 15$ of the well-concoctedness of the semen only to conclude by saying (b17-18) what, when it is well concocted, the movement of the male will effect; the remark at b18-20 is then fully in place, as indicating that no gap has in fact been left 
open in the explanation just given between the semen (and its features) and the formative movements.

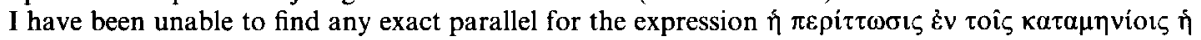
$\sigma \pi \varepsilon \rho \mu \alpha \tau ו \kappa n$ (referring either to the semen or to the female generative residue), but Aristotle does of course speak frequently enough of a mixture of the two residues when conception occurs (e.g. 728a2930 ), and he does occasionally mention semen being in the catamenia under such circumstances (e.g. 727a17-18). So neither Aristotle's usage nor his general theoretical position throws up any obstacle to finding here the reference to the semen that the surrounding context requires.

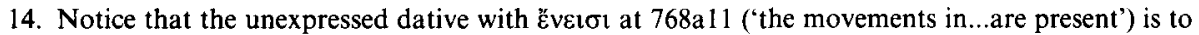

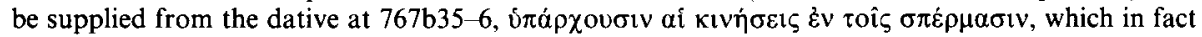
this sentence partially repeats. Since $\sigma \pi \varepsilon \varepsilon^{2} \mu \alpha \sigma v$ at $767 \mathrm{~b} 36$ is the semen (only), so must the intended reference to seminal fluid at $768 \mathrm{a} 11$ be. This is added confirmation, if any were needed, for my

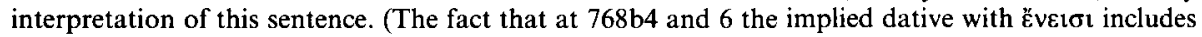

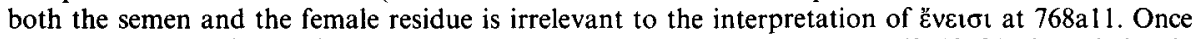
movements in the female fluid are introduced into Aristotle's account, at 768a18-21, they obviously fall within the scope of the general principles about actual and potential movements first set out for the male fiuid alone at 767b35-7 and 768a1 1-14, and he simply takes note of this fact at $768 \mathrm{~b} 4$ and 6.)

15. I translate Drossaart Lulofs' text. But I wonder whether one ought, instead of excising кai غ̇ $\pi \grave{i}$

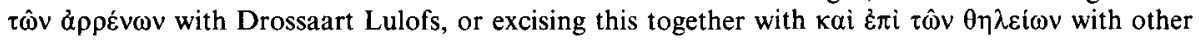
editors, to retain the manuscript reading, changing only the second $\alpha \alpha i$ of a 18 to $\tilde{\sigma} \sigma \pi \varepsilon \rho$, thus giving the sense: 'And in this way too, on the side of the females as on that of the males...'. Or mss. might

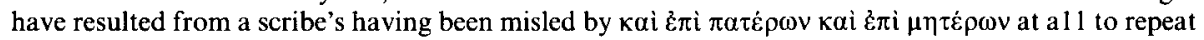
that construction here by altering $\ddot{\sigma} \pi \varepsilon \rho$ to $\kappa a i$.

16. Since it says less about what in or about the semen enables it to do the required work, the first conception may seem less satisfactory than the second. On the other hand, it may be a virtue of the first conception that its commitments here are less substantial. At any rate, one might feel some discomfort with the second conception's idea that the semen has some sort, however general, of physically realized underlying movements for resemblances to any of the potential mothers' families. If that is the alternative, then perhaps the more non-committal first conception is philosophically and scientifically preferable after all.

17. It is noteworthy that though in the first words of this paragraph Aristotle offers to explain the slackening of movements in general (and so, among others the slackening of the movements in the catamenia mentioned at 768a 18-21) in fact he goes on to discuss only the slackening of the movements in the semen - these are the only movements that are active, nolouvvia of anything. This confirms the secondary rôle assigned in his theory to movements in the catamenia. It also fits in well with the attribution to the semen of potential movements somehow corresponding to them: in effect, in discussing only the slackening of the semen's movements he will have covered the whole range of the phenomena.

18. One should not object to this analogy on the ground that it compares the semen, which Aristotle treats as merely a tool used by the father (the actual 'artisan'), to an artisan (the sculptor) rather than to his tools (chisel etc.). For as I have pointed out Aristotle is evidently thinking of the semen as a highly refined, fully programmed and self-starting tool not controlled by the father himself once it is set loose, and so much more like the sculptor himself than his chisel (which is presumably why he

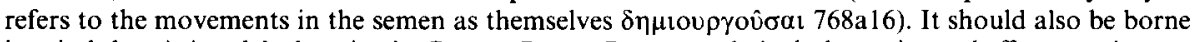
in mind that Aristotle's doctrine in Gen. et Corr. I, 7 apparently includes reciprocal effects not just on the doctor's or the sculptor's tools, but also on these practitioners themselves: $324 \mathrm{~b} 3-13$.

19. In the Hippocratic treatise On Generation I can find no clear reference to the first type of resemblance. All the emphasis, at any rate, is on ways the offspring takes after one or the other parent in features distinctive of and more or less special to that parent. See sects. 8 and 9. 
20. Balme (1984), reprinted in Gotthelf and Lennox (1987) 292.

21. I mean only to be reporting Aristotle's view, not defending it. Since for most individual animals for most of their life-spans eye-colour remains the same, through growth, etc., it must continue to be true that the combination of the auxetic movements in the animal's blood and the availability ofmaterial for adding to and maintaining the eye has the effect of preserving this colour. It is not clear that he has a good explanation for why this happens, if the form is not aiming at this result.

22. In revising this paper for publication I have been aided by comments of Myles Burnyeat, Nicholas Denyer, Geoffrey Lloyd, and Robert Wardy when it was read to the Society. I have been greatly helped also by further written comments of Prof. Lloyd and by his paper 'Aristotle's zoology and his metaphysics: the status quaestionis' presented to a conference at Oléron, France in July, 1987, and forthcoming in its proceedings. Finally, sharp questioning by Jonathan Barnes, David Charles and Lindsay Judson when I read the paper at Balliol in May 1988 led to significant improvements in sections $\mathrm{V}$ and VI. 